\title{
STRATEGI PENGEMBANGAN USAHA BUDIDAYA BAWANG MERAH DI KABUPATEN TABALONG
}

\author{
(The Development Strategy Onion Cultivation in Tabalong)

\section{Purna Kusumayana ${ }^{1)}$ dan Ronna Vaty Redhanie ${ }^{2)}$}

\author{
1) Dosen Program Studi Agribisnis, Sekolah Tinggi Ilmu Pertanian Amuntai (STIPER) Amuntai \\ ${ }^{2)}$ Mahasiswa Program Studi Agribisnis, Sekolah Tinggi Ilmu Pertanian Amuntai (STIPER) Amuntai \\ e-mail : kusumayanapurna@yahoo.com
}

\begin{abstract}
The state of onion cultivation in the village is good enough, This village is economically advantageous to be developed and cultivated. From the results of calculations using SWOT analysis, then the values obtained from the analysis ofinternal factors (IFAS) by 2.80, then and for the value of the analysis of external factors (EFAS) by 2.76, meaning commodity onion has acomparative advantage the result is not only meet the needs of the region concerned but can be exported out of the territory Tabalong.

The development strategy onion cultivation in Tabalong is aggressive strategy with more focus on SO strategy (Strength-Opportunities), by using force to take advantage of existing opportunities. Strategies (Strength-Opportunities): Develop and improve the image onion farming, develop agro-onion, optimizing groups for integrated pest management, improving the competence of the Human Resource, optimizing the coordination of relevant agencies, expanding markets for the products of onion.
\end{abstract}

Keywords : onion cultivation, SWOT analysis, internal and external factors

\begin{abstract}
Abstrak
Keadaan budidaya bawang merah di Kabupaten Tabalong cukup baik, secara ekonomis menguntungkan untuk dikembangkan dan diusahakan. Dari hasil perhitungan dengan mengunakan analisa SWOT, maka diperoleh nilai dari analisis internal faktor (IFAS) sebesar 2,80, maka dan untuk nilai dari analisis eksternal faktor (EFAS) sebesar 2,76, maka komoditas bawang merah tersebut memiliki keunggulan komparatif yang hasilnya tidak hanya dapat memenuhi kebutuhan daerah yang bersangkutan tetapi dapat diekspor ke luar wilayah Kabupaten Tabalong.

Strategi pengembangan budidaya bawang merah di Kabupaten Tabalong adalah strategi agresif dengan lebih focus kepada strategi SO (strenght-Opportunities), yaitu dengan mengunakan kekuatan untuk memanfaatkan peluang yang sudah ada. Strategi (Strenght-Opportunities): mengembangkan dan meningkatkan citra usahatani bawang merah, mengembangkan agroindustri bawang merah, mengoptimalkan kelompok untuk pengendalian hama terpadu, peningkatan kompetensi Sumber Daya Manusia, optimalisasi koordinasi instasi terkait, memperluas pasar bagi produk bawang merah.
\end{abstract}

Kata kunci : bawang merah, analisis SWOT, faktor eksternal internal

\section{PENDAHULUAN}

Komoditas hortikultura yang terdiri dari buah-buahan, sayuran, tanaman hias, dan tanaman obat mempunyai potensi untuk dikembangkan sebagai usaha agribisnis. Salah satu jenis tanaman hortikultura tersebut adalah bawang merah (Allium ascolonium L) yang tergolong tanaman semusim dan termasuk sayuran rempah (Ditjen Tanaman Pangan dan Hortikultura, 1997).
Tanaman bawang merah di Indonesia telah lama diusahakan oleh petani sebagai usahatani yang bersifat komersial, yang sebagian besar atau seluruh hasil produksinya ditujukan untuk memenuhi permintaan. Namun berdasarkan hasil pemantauan Direktorat Jendral Bina Produksi Hortikultura, produksi bawang merah di Indonesia menurut propinsi mengalami fluktuasi yang sangat signifikan. 
Kabupaten Tabalong merupakan salah satu daerah penghasil bawang merah di provinsi Kalimantan Selatan sejak tahun 2014, daerah tersebut mempunyai prospek cukup baik untuk pengembangan komoditi bawang merah. Berikut perkembangan luas panen dan produksi bawang merah di Kabupaten Tabalong berdasarkan data Dinas Tanaman Pangan Kabupaten Tabalong pada tahun 2014 luas panen sebesar 5 Ha dengan produksi 40 ton dan pada tahun 2015 luas panen sebesar $5 \mathrm{Ha}$ dengan produksi 40 ton.

Peningkatan luas panen dan produksi selama dua tahun penanaman menunjukkan tanaman bawang merah masih terus dapat dikembangkan dilihat dari konsumsi bawang merah di kabupaten yang cukup tinggi dan pasokan bawang merah yang masih didatangkan dari luar daerah sementara lahan tanam masih tersedia cukup.

Berdasarkan latar belakang tersebut maka rumusan masalah dalam penelitian ini adalah 1) faktor internal dan eksternal apa dalam usaha pengembangan bawang merah di Kabupaten Tabalong?, dan 2) bagaimana strategi pengembangan usaha bawang merah di Kabupaten Tabalong.

\section{TINJAUAN PUSTAKA}

\section{Syarat Tumbuh}

Tanaman bawang merah biasanya lebih bisa tumbuh pada tanah yang gembur, subur, dan banyak mengandung bahan-bahan berjenis organik seperti tanah lempung berdebu atau lempung berpasir. Jenis tanah tersebut yang terpenting harus mempunyai struktur bergumpal dan keadaan air tanahnya tidak menggenang (stagnasi), oleh karena itu pada daerah lahan yang sering tergenang atau daerah lahan yang becek harus dibuat saluran pembuangan air (drainase) yang baik. Derajat keasaman tanah $(\mathrm{pH})$ antara 5,5-6,5.

Suhu udara yang baik untuk pertumbuhan tanaman bawang merah antara $25-32^{\circ} \mathrm{C}$ dengan iklim kering. Tanaman bawang merah lebih menghendaki daerah yang terbuka dengan penyinaran $\pm 70 \%$. Apabila terlindung umbinya kecil.

\section{Konsep Agribisnis}

Agribisnis dibagi menjadi tiga sektor ekonomis, yaitu meliputi seluruh sektor bahan masukan usahatani (input), produksi (farm), dan yang memasak bahan masukan usahatani/pemroresan, penyebaran, penjualan baik borongan dan eceran oleh produsen ke konsumen akhir (output) (Downey, 1998).

Menurut Badan Agribisnis (1995), agribisnis adalah salah satu kesatuan sistem yang terdiri dari beberapa subsistem yang saling terkait erat, yaitu : Subsistem pengadaan sarana produksi, Subsistem usahatani, Subsistem pasca panen dan pengolahan, Subsistem pemasaran, Subsistem jasa dan penunjang.

\section{KERANGKA PEMIKIRAN TEORITIS}

\section{Analisa SWOT}

Analisis SWOT adalah metode perencanaan strategis yang digunakan untuk mengevaluasi kekuatan (strengths), kelemahan 
(weaknesses), peluang (opportunities), dan ancaman (threats) dalam suatu proyek atau suatu spekulasi bisnis. Keempat faktor itulah yang membentuk akronim SWOT (strengths, weaknesses, opportunities, threats).

Menurut rangkuti (2006), matriks SWOT menggambarkan secara jelas bagaimana peluang dan ancaman eksternal yang dihadapi perusahaan dapat disesuaikan dengan kekuatan dan kelemahan yang dimiliki. Matriks ini menghasilkan empat set kemungkinan alternatif strategi, yaitu S-O (Srenghts-Opportunities), W-O (Weaknesses-Threans), S-T (StrenghtsThreats) dan W-T (Weaknesses-Threats).

Selanjutnya dengan pendekatan matriks faktor strategi eksternal (External Factor Analysis Summary $=E F A S$ ) dan matriks faktor strategi internal (Internal Factor Analysis Summary $=$ IFAS) dapat diperoleh berbagai alternatif strategi. Strategi EFAS adalah strategi yang digunakan untuk merumuskan dan mengkaji faktor kekuatan dan kelemahan yang ada.

\section{METODOLOGI}

Penelitian ini dilaksanakan di Kabupaten Tabalong. Waktu penelitian dimulai dari bulan Juni 2015 sampai dengan selesai yaitu mulai dari persiapan, pengumpulan data, pengolahan data sampai dengan tahapan penyusunan laporan.

\section{Jenis dan Sumber Data}

Data yang dikumpulkan dalam penelitian terdiri dari data primer dan data sekunder. Data primer diperoleh langsung melalui wawancara dengan petani. Sedangkan data sekunder diperoleh dari instansi-instansi terkait serta melalui pustaka dari berbagai media yang berhubungan dengan penelitian.

\section{Metode Pengumpulan Data}

Penelitian ini merupakan penelitian deskriptif kualitatif. Pemilihan responden bertujuan untuk mengetahui faktor-faktor eksternal dan internal yang berpengaruh terhadap pengembangan budidaya bawang merah. Berikut ini daftar responden yang diambil.

Tabel 2. Responden Penelitian

\begin{tabular}{|c|c|c|}
\hline No & Responden & Jumlah \\
\hline 1. & Petani & 10 orang \\
\hline 2. & PPL & 1 orang \\
\hline 3. & Dinas Pertanian & 2 orang \\
\hline \multirow[t]{2}{*}{4.} & Kepala Desa & 1 orang \\
\hline & Total & 14 orang \\
\hline
\end{tabular}

Sumber : Pengolahan Data Primer, 2015

\section{Analisis Data}

Proses penyusunan perumusan strategi melalui tiga tahap pengambilan keputusan.

\section{Pengumpulan Data}

Pengumpulan data dilakukan terhadap :

a. Faktor internal, terdiri dari kekuatan dan kelemahan

b. Faktor eksternal, terdiri dari peluang dan ancaman.

c. Penyusunan dan perhitungan.matriks faktor strategi internal (IFAS) dan eksternal (EFAS) 
Tabel 3. Model IFAS

\begin{tabular}{|c|c|c|c|}
\hline $\begin{array}{c}\text { Faktor-faktor } \\
\text { Strategi } \\
\text { Internal } \\
\end{array}$ & Bobot & Rating & $\begin{array}{c}\text { Bobot } \\
\mathbf{x} \\
\text { Rating }\end{array}$ \\
\hline \multicolumn{4}{|l|}{ KEKUATAN : } \\
\hline \multicolumn{4}{|l|}{$1 \ldots \ldots \ldots \ldots$} \\
\hline \multicolumn{4}{|l|}{$2 \ldots \ldots \ldots \ldots$} \\
\hline \multicolumn{4}{|l|}{$3 \ldots \ldots \ldots \ldots$} \\
\hline \multicolumn{4}{|l|}{ KELEMAHAN : } \\
\hline \multicolumn{4}{|l|}{$1 \ldots \ldots \ldots \ldots \ldots$} \\
\hline \multicolumn{4}{|l|}{$2 \ldots \ldots \ldots \ldots \ldots$} \\
\hline $3 \ldots \ldots \ldots \ldots \ldots$ & & & \\
\hline Total & & & \\
\hline
\end{tabular}

Sumber : Rangkuti, 2006

Tabel 4. Model EFAS

\begin{tabular}{|c|c|c|c|}
\hline $\begin{array}{c}\text { Faktor-faktor } \\
\text { Strategi } \\
\text { Eksternal }\end{array}$ & Bobot & Rating & $\begin{array}{c}\text { Bobot } \\
\mathbf{x} \\
\text { Rating }\end{array}$ \\
\hline \multicolumn{4}{|l|}{ PELUANG : } \\
\hline \multicolumn{4}{|l|}{$1 \ldots \ldots \ldots \ldots$} \\
\hline \multicolumn{4}{|l|}{$2 \ldots \ldots \ldots \ldots \ldots$} \\
\hline \multicolumn{4}{|l|}{$3 \ldots \ldots \ldots \ldots$} \\
\hline \multicolumn{4}{|l|}{ ANCAMAN : } \\
\hline \multicolumn{4}{|l|}{$1 \ldots \ldots \ldots \ldots \ldots$} \\
\hline \multicolumn{4}{|l|}{$2 \ldots \ldots \ldots \ldots \ldots$} \\
\hline $3 \ldots \ldots \ldots \ldots \ldots$ & & & \\
\hline Total & & & \\
\hline
\end{tabular}

Sumber : Rangkuti, 2006

Berdasarkan tabel 3 dan 4, tahap yang dilakukan dalam menentukan faktor strateginya adalah menentukan faktor-faktor yang menjadi kekuatan, kelemahan serta peluang dan ancaman dalam kolom 1, lalu di beri bobot pada kolom 3. Secara matematis penentuan bobot dapat dilakukan dengan mengunakan rumus sebagai berikut :

$$
\text { Bobot }=\frac{\text { Rating } \mathrm{x} \text { total bobot }}{\text { Total Rating }}
$$

\section{Cara Perhitungan IFAS}

a. Tentukan faktor-faktor yang menjadi kekuatan serta kelemahan dalam kolom 1. Beri bobot masing-masing faktor tersebut dengan skala mulai dari skala 1, 2,3 dengan keterangan tiap skala sebagai berikut :

$1=$ jika indikator horizontal kurang penting dari pada indikator vertikal

$2=$ jika indikator horizontal sama penting dengan indikator vertikal

3 = jika indikator horizontal lebih penting dari pada indikator vertikal

Pemberian bobot setiap faktor dengan skala mulai dari 0, 0 (tidak penting) sampai 1 , 0 (paling penting). Pemberian bobot ini berdasarkan pengaruh faktor-faktor tersebut terhadap posisi strategi usaha. Jumlah bobot yang diberikan harus sama dengan 1,0 .

b. Hitung rating (dalam kolom 3) untuk masing-masing faktor dengan memberikan skala mulai dari 1,2,3,4 berdasarkan pengaruh faktor tersebut terhadap kondisi pengembangan bawang merah yang bersangkutan. Menurut umar (2010), skala rating untuk matrik IFAS (kekuatan dan kelemahan) adalah :

1 = kelemahan utama/kondisi buruk

$2=$ kelemahan kecil/kondisi biasa saja

3 = kelemahan kecil/kondisi baik

4 = kekuatan besar/kondisi sangat baik

c. Kaitan bobot pada 2 kolom rating dengan rating pada kolam 3, untuk memperoleh faktor pembobotan dalam kolom 4 . Hasilnya berupa faktor skor pembobotan untuk masing-masing faktor yang nilainya bervariasi mulai dari 1 (terendah) sampai dengan 4 (tertinggi) dengan nilai rata-rata 2,5. Artinya semakin tinggi skor pembobotan mengenditifikasikan usaha 
pengembangan bawang merah merespon kekuatan dan kelemahan atau peluang dan ancaman dengan baik.

d. Jumlah skor pembobotan (pada kolom 4), untuk memperoleh total skor pembobotan bagi yang bersangkutan, total skor berkisar antara 1 sampai 4 dengan rata-rata 2,5. Jika total skor $(3,0-4,0)$ berarti kondisi pengembangan bawang merah tinggi/kuat $(2,0-2,99)$ berarti kondisi internal ratarata/sedang dan $(1,0-1,99)$ berarti kondisi internal rendah/lemah.

\section{Matrik SWOT}

Berdasarkan analisis lingkungan internal dan eksternal yang telah dilakukan dibangun pula sebuah matriks SWOT yang bertujuan untuk mengembangkan empat alternatif strategi yang berdasarkan kekuatan, kelemahan, peluang dan ancaman bagi perusahaan. Keempat alternatif strategi tersebut antara lain adalah strategi SO (Strenght - Oppurtunity), strategi WO (Weakness - Oppurtunity), strategi ST (Strenght - Threat), strategi WT (Weakness - Threat). Matriks SWOT yang dibangun dalam rangka formulasi strategi ini bersifat melengkapi (complementary) terhadap analisis matriks I-E yang telah dilakukan sebelumnya.

\section{HASIL DAN PEMBAHASAN}

Hasil analisa SWOT usaha budidaya tanaman bawang merah Kabupaten Tabalong diketahui sebagai berikut :

1. Kekuatan : pengalaman berusahatani, penggunaan benih unggul, tersedianya tenaga kerja, usia petanimasih produktif, peningkatan pendapatan.

2. Kelemahan : penggunaan teknologi masih sederhana, tingkat pendidikan petani rendah, modal kurang, sistem pemasaran, kepengurusan kelompok belum optimal.

3. Peluang : permintaan pasar tinggi, lahan tersedia luas,intensitas penyuluhan oleh PPL yang kontinu, meningkatnya pengetahuan masyarakat, dukungan kebijakan pemerintah dan kelembagaan.

4. Ancaman : serangan hama dan penyakit, akses transportasi, analisa kepentingan kelompok, kelangkaan pupuk, fluktuasi harga bawang merah.

\section{Penyusunan IFAS dan EFAS}

Setelah faktor strategi internal dan eksternal diidentifikasi, selanjutnya dilakukan pembobotan dan rating.

Tabel 5. Matrik SWOT

\begin{tabular}{|c|c|c|c|}
\hline $\mathbf{I}$ & \multicolumn{2}{|l|}{ STRENGTHS (S) } & WEAKNESSES (W) \\
\hline \multirow[b]{2}{*}{$\begin{array}{c}\text { OPPORTUNITIES } \\
(\mathrm{O})\end{array}$} & \multicolumn{2}{|l|}{ STRATEGI SO } & STRATEGI WO \\
\hline & $\begin{array}{l}\text { Ciptakan strategi } \\
\text { menggunakan kekuatan } \\
\text { memanfaatkan peluang }\end{array}$ & $\begin{array}{r}\text { yang } \\
\text { untuk }\end{array}$ & $\begin{array}{l}\text { Ciptakan strategi yang } \\
\text { memanimalkan kelemahan } \\
\text { memanfaatkan peluang }\end{array}$ \\
\hline \multirow{2}{*}{$\begin{array}{c}\text { THREATHS } \\
\text { (T) }\end{array}$} & \multicolumn{2}{|l|}{ STRATEGI ST } & STRATEGI WT \\
\hline & $\begin{array}{l}\text { Ciptakan strategi } \\
\text { menggunakan kekuatan } \\
\text { mengatasi ancaman }\end{array}$ & $\begin{array}{r}\text { yang } \\
\text { untuk }\end{array}$ & $\begin{array}{ll}\text { Ciptakan strategi yang } \\
\text { meminimumkan kelemahan dan } \\
\text { menghindari ancaman }\end{array}$ \\
\hline
\end{tabular}

Sumber : Rangkuti, 2006 
Tabel 6. Model IFAS

\begin{tabular}{lccc}
\hline \multicolumn{1}{c}{ Faktor-faktor Strategi Internal } & Bobot & Rating & Bobot x Rating \\
\hline KEKUATAN : & 0,10 & 3 & \\
1. Pengalaman & 0,15 & 4 & 0,30 \\
2. Benih unggul & 0,14 & 4 & 0,60 \\
3. Tenaga kerja & 0,08 & 3 & 0,56 \\
4. Usia produktif & 0,14 & 4 & 0,24 \\
5. Pendapatan & & & 0,56 \\
\hline KELEMAHAN : & 0,09 & 1 & 0,09 \\
1. Teknologi sederhana & 0,08 & 1 & 0,08 \\
2. Tingkat pendidikan & 0,10 & 2 & 0,20 \\
3. Modal & 0,06 & 1 & 0,06 \\
4. Pemasaran & 0,06 & 2 & 0,12 \\
5. Kepengurusan & $\mathbf{1}$ & & $\mathbf{2 , 8 0}$ \\
\hline \multicolumn{1}{c}{ TOTAL } & & &
\end{tabular}

Sumber : Rangkuti, 2006

Tabel 7. Model EFAS

\begin{tabular}{lccc}
\hline Faktor-faktor Strategi Eksternal & Bobot & Rating & Bobot x Rating \\
\hline PELUANG : & 0,18 & 3 & \\
1. Pasar & 0,12 & 4 & 0,54 \\
2. Lahan & 0,03 & 3 & 0,48 \\
3. Penyuluh & 0,08 & 4 & 0,09 \\
4. Pengetahuan & 0,15 & 4 & 0,32 \\
5. Kebijakan & & & 0,60 \\
\hline ANCAMAN : & 0,07 & 1 & 0,07 \\
1. Hama \& Penyakit & 0,05 & 1 & 0,05 \\
2. Transportasi & 0,14 & 2 & 0,28 \\
3. Analisa kepentingan & 0,15 & 2 & 0,30 \\
4. Kelangkaan pupuk & 0,03 & 1 & 0,03 \\
5. Fluktuasi harga & $\mathbf{1}$ & & $\mathbf{2 , 7 6}$ \\
\hline \multicolumn{1}{c}{ TOTAL } & & & \\
\hline
\end{tabular}

Sumber : Rangkuti, 2006

\section{Penentuan Posisi SWOT dan Penentuan Alternatif Strategi}

Posisi sesuai diagram SWOT diambil dari total nilai matriks IFAS dan EFAS yaitu 2,80 dan 2,76 yang menunjukkan bahwa usaha budidaya bawang merah terletak pada kuadran I (SO-STRATEGI) yang artinya usaha budidaya bawang merahsangat menguntungkan, karena punya kekuatan dan peluang yang lebih besar dibandingkan dengan kelemahan dan ancamannya.
Strategi SO dibuat berdasarkan jalan pikiran pengembangan usaha budidaya kedepannya, yaitu dengan mengunakan seluruh kekuatan untuk memanfaatkan peluang.

Beberapa alternatif strategi yaitu :

- Mengembangkan dan meningkatkan citra usahatani bawang merah dengan sumberdaya yang terkait dalam pengembangan budidaya. 
- Mengembangkan agroindustri bawang merah termasuk peningkatan kapasitas produksi, upaya ini akan menstabilkan harga bawang merah, terutama jika ada kerjasama petani dengan pengusaha.

- Mengoptimalkan kelompok untuk pengendalian hama terpadu dalam pengembangan bawang merah.

- Meningkatkan pembinaan agroindustri bawang merah terutama peningkatan teknologi sehingga pengolahannya menjadi lebih modern dan kapasitas produksi yang optimal dan menghasilkan produk yang kualitasnya dan menjadi produk khas daerah seperti daerah Kandangan seperti halnya dodol.

- Peningkatan kompetensi Sumber Daya Manusia melalui pelatihan-pelatihan mengenai prospek kedepanya agar pengembangan budidaya bawang merah lebih meningkat.

- Optimalisasi koordinasi instansi terkait, yaitu dengan cara mengoptimalisasi hubungan baik dengan instansi-instasi yang ada sehingga prospek pengembangan budidaya bawang merah dapat lebih meningkat.

- Memperluas pasar bagi produk bawang merah sehingga dapat di pasarkan ke luar wilayah Kabupaten Tabalong dengan tingkat harga dan volume yang optimal.

\section{SIMPULAN DAN SARAN}

\section{Simpulan}

1. Analisis faktor internal (IFAS) diperoleh 2,80 dan nilai dari analisis faktor internal (EFAS) sebesar 2,76. Hasil tersebut menunjukkan bahwa komoditas bawang merah usaha budidaya bawang merah cukup menjanjikan untuk dikembangkan dengan mempotensikan keunggulan dan peluang yang ada.

2. Strategi pengembangan budidaya bawang merah di Kabupaten Tabalong adalah strategi agresif dengan lebih fokus kepada strategi SO (Strenght-Opportunities), yaitu dengan mengunakan kekuatan untuk memanfaatkan peluang yang sudah ada. Strategi yang dimaksud adalah mengembangkan dan meningkatkan citra usahatani bawang merah, mengembangkan agroindustri bawang merah, mengoptimalkan kelompok untuk pengendalian hama terpadu, peningkatan kompetensi sumber daya manusia, optimalisasi koordinasi dengan instasi terkait dan memperluas pasar bagi produk bawang merah

\section{Saran}

1. Petani pengusaha budidaya bawang merah hendaknya lebih memperhatikan faktor kekuatan dan peluang yang ada sehingga pendapatannya bisa lebih optimal.

2. Perlu dukungan penuh dari pemerintah untuk pengembangan bawang merah, mengingat prospek bawang kedepannya sangat baik. 


\section{DAFTAR PUSTAKA}

Dinas Tanaman Pangan dan Hortikultura. 2015. Laporan Tahunan. Disperta. Tabalong.

Downey, W. David, Erickson, Steven P., 1989. Manajemen Agribisnis. Penerbit Erlangga, Jakarta.

Firdaus, Muhammad, 2008.Manajemen Agribisnis.B umi Aksara, Jakarta

Hernanto,F., 1989. Ilmu Usahatani. Penebar Swadaya, Jakarta.

Ikhsan Nur, 2004. Tantangan dan Strategi Pengembangan Agribisnis. Jurnal Ekonomi, Bisnis dan Akuntansi Palu.

Kuncoro, M., 2006. Strategi Bagaimana Meraih Keunggulan Kompetitif. Penerbit Erlangga, Jakarta.

Rangkuti, F., 2006. Analisis SWOT Teknik Membedah Kasus Bisnis. Gramedia, Jakarta.

Renville, S., 1997. Pengantar Manajemen Agribisnis. Gadjah Mada University Press, Yogyakarta.

Rukmana, R., 1994. Budidaya Tanaman Bawang Merah. Kanisius, Yogyakarta.

Setyobudi, W., 2010.http : //inspirewhy.com/Teknik-ModerasiFocus-Group-Discussion-fgd.Diakses tanggal 29 Maret 2010.

Siagian, P. , 2007. Manajemen Stratejik. Bumi Aksara, Jakarta.

Soekartawi, 1995. Analisis Usahatani. Universitas Indonesia Press. Jakarta. 